$A R T I I C U L O O H E$ I NVESTI G A C I Ó N $\begin{array}{llllllllllllll}C & I & E & N & T & I & F & I & C & A & Y\end{array}$

TEC N O L Ó G I C A

\title{
LA CÁTEDRA LOCAL, COMO ESTRATEGIA DE AULA, PARA FORMAR IDENTIDAD HISTÓRICA Y CULTURAL ${ }^{1}$.
}

\author{
THE LOCAL CATHEDRA, AS A CLASSROOM STRATEGY, TO FORM \\ HISTORICAL AND CULTURAL IDENTITY
}

Por: Yolima Rodríguez Ramírez*

* Docente Institución Educativa Dorada, La Dorada, Caldas; Licenciada en Ciencias sociales y aspirante a magister de historia de la Universidad Tecnológica de Pereira.
1 Proyecto de aula aplicado a grado 7, Institución Educativa Dorada
Recibido: 12 de diciembre de 2017 - Aprobado: 28 de abril de 2018

\section{RESUMEN}

El artículo busca resaltar la importancia de la historia barrial y local del municipio de La Dorada desde un ejercicio investigativo formativo en la institución Educativa Dorada, donde los estudiantes de grado séptimo y once recolectaron diversas fuentes de información y desarrollaron diferentes actividades de exposición de sus resultados para así dar a comprender a su comunidad educativa su propia cotidianidad y su visión de la historia local. Desde el aula se puede hacer visible esa Historia que no se ha contado, la de las personas comunes, de las que han presenciado o no y que de una u otra manera se convirtieron en actores pasivos o activos de ella. La Dorada, la segunda ciudad en importancia del departamento de Caldas, después de Manizales su capital, es un municipio con una amplia población estudiantil, la cual es bastante flotante debido a diversos factores económicos y sociales, como lo son las fuentes de empleo o el conflicto armado en la región.

La escuela entonces como artífice de la reconstrucción de la historia desde abajo, donde los estudiantes comprometidos con la investigación histórica hallaron fuentes como la memoria colectiva oral, la de sus vecinos, familiares y conciudadanos que les permitieron redescubrir su pasado y, de paso, darle una nueva dinámica a las clases de sociales, ya que ellos al asumir el rol del oficio del historiador lograron acercarse a un pasado oculto y desconocido, pero latente en sus vidas, que al ser analizado conllevan al entendimiento de las dinámicas que se viven día a día en el municipio.

Palabras clave: Historia local, Enseñanza-aprendizaje, Investigación social, Sentido de pertenencia, Identidad, pensamiento crítico y método histórico.

\begin{abstract}
The article seeks to highlight the importance of the neighborhood and local history of the municipality of La Dorada from a formative research exercise in the educational institution Dorada, where the seventh and eleventh grade students collected various sources of information and developed different activities to expose their results in order to tell their educational community their own daily life and their vision of local history. From the classroom you can make visible that untold History, that of ordinary people, those who have witnessed or not and who in one way or another became passive or active actors of it. La Dorada, the second city in importance of the department of Caldas, after Manizales its capital, is a municipality with a large student population, which is quite floating due to various economic and social factors, such as sources of employment or armed conflict in the region.
\end{abstract}


The school then as the architect of the reconstruction of history from below, where students committed to historical research found sources such as oral collective memory, the one of their neighbors, relatives and fellow citizens that allowed them to rediscover their past and, incidentally, give it a new dynamic to the social classes, by assuming the role of the historian's job they managed to approach a hidden and unknown past, but latent in their lives, that when analyzed lead to an understanding of the dynamics that are experienced day after day the municipality.

Keywords: Local history, teaching - learning, social research, sense of belonging, identity and critical thinking and historical method.

\section{Introducción}

ste artículo inicia con la historia de la educación en Colombia y las
formas como fueron evolucionando a través del tiempo, hasta darle
valor significativo a la nueva historia, resaltando el campo de acción
de gran amplitud formativa y conceptual que establecen en la actualidad
los estándares en las Ciencias Sociales del Ministerio de Educación Nacional
(MEN), ofrece una gran apertura en la enseñanza de contenidos y el poder
desarrollar proyectos de aula que pretenden despertar el espíritu investigador
en los educandos.

Se aborda la importancia de la historia y de las microhistorias para formar identidad histórica y cultural y sentido de pertenencia. Para alcanzar las metas propuestas en el plan de área que se implementó sobre cátedra local doradense en la Institución Educativa Dorada, se diseñaron secuencias de aprendizaje coherentes con los estándares para grado 7, con la utilización del método histórico para iniciar a los educandos en la investigación social, además, se integraron a este proyecto de ciencias sociales otras áreas del conocimiento tales como artística y ética.

La presente propuesta surge de la premisa de que cuando un pueblo carece de memoria, de referentes históricos, no puede ocupar el lugar que le pertenece, ni garantizar su sobrevivencia en el tiempo, pues como afirman Infante y Hernández (2011) retomando a Casaus (1996),

"Cancelar la historia, bloquear la memoria es una forma terrible de abandonar nuestros valores, de abandonarnos memoria viva ha dicho Eduardo Galeano, porque nos impulsa a reflexionar sobre nuestro pasado lejano y reciente. Hay que rescatar lo activo de la memoria y no dar cabida a la nostalgia paralizadora del pasado (párr. 11)." 
Con base en lo anterior surgen algunos interrogantes tales como: ¿cuáles son las representaciones sociales de la identidad doradense en la escritura de la historia del municipio? ¿Cómo se puede articular la perspectiva de los jóvenes doradense de la Institución Educativa Dorada en la construcción de una historia local más crítica e incluyente?

Después de aplicar una encuesta a nuestros educandos de grados diferentes, nos encontramos que el 75\% de ellos desconocen totalmente la historia local doradense. En este sentido, el nombre del fundador del municipio, las características predominantes de la economía local y regional, la fecha de fundación, la ubicación geográfica y su importancia histórica a través del tiempo, el origen del nombre del municipio, los barrios, etc., no son aspectos de gran interés para ellos.

Cabe señalar que La Dorada es conocida como "El corazón de Colombia" gracias a su ubicación geográfica, pues tiene acceso por el oriente con Caldas, por el norte con Tolima, por el suroccidente con Santander, por el noroccidente con Cundinamarca, por el suroriente con Antioquia y el occidente de Boyacá, además de tener una cercanía con Bogotá y Medellín. Asimismo, el municipio cuenta con un paisaje natural sobresaliente que, sumado a la tradición histórica del puerto sobre el majestuoso río Magdalena y el rápido acceso a las principales ciudades del país, le permiten potenciar su capacidad de región habilitada para múltiples desarrollos, entre ellos el ecoturismo. Esta misma capacidad genera que su población sea flotante, a causa de las dinámicas económicas que estimulan los constantes procesos de migración, lo cual afecta la cotidianidad de la Institución Educativa Dorada, y por consiguiente, el arraigo y sentido de pertenencia por el municipio por parte de los educandos. Otro aspecto importante que puede explicar esta falta de conocimiento sobre la localidad es que en el plan de área (Ciencias Sociales) de la Institución, solo se enseña lo elemental sobre la localidad en básica primaria y no se vuelve a abordar en básica y media secundaria. Ante esta situación, es de vital importancia preguntarse desde el aula por los procesos de formación de las identidades culturales en los jóvenes y cómo los maestros inciden en estos aspectos, y de qué manera podemos implementar la cátedra local doradense en un proyecto de aula que involucre al adolescente como un investigador de su historia, ya que el municipio de La Dorada ha atravesado a lo largo de su historia por una serie de procesos de expansión territorial y de globalización, originados por su ubicación geográfica y por la temprana aparición del ferrocarril, la navegación por el río Magdalena y las dinámicas económicas 
que cambian con el pasar de los años y que afectan los procesos históricos y culturales de la localidad y su población.

Esta experiencia de aula nace como proyecto al estar cursando la maestría en historia que a través de los seminarios cambian totalmente la perspectiva que como docente tenia para orientar las ciencias sociales a los educandos, con un conocimiento más cualificado y las herramientas de historiografía, y didáctica de la historia, permitiendo desde esa nueva óptica llevar lo aprendido en la Universidad y proyectar un quehacer pedagógico más riguroso y enriquecido al llevar a la práctica un proyecto de investigación histórica, porque con base en lo escrito por Sanchez, (2014): "Antes que nada diremos que enseñar a investigar es una actividad compleja y laboriosa. Su complejidad resulta del objeto mismo de la enseñanza; investigar es un saber práctico, es un saber-hacer "algo"; es decir, generar conocimientos nuevos en un campo científico particular" (p.21).

"La historia es un constructo teórico que se nutre de la investigación del pasado, la cual se sustenta sobre diversas fuentes de información (archivos, cartas, carteles de propaganda, testamentos, tratados, fotografías, estadísticas, panfletos, etc.). Desde este punto de vista, la Historia no es una realidad estática, ya que no es el pasado en sí mismo, sino que es la investigación de ese pasado. En el proceso de enseñanza aprendizaje de las ciencias sociales y en especial de la historia, es necesario reinventarse $y$ renovar el pensamiento y lo que concebimos como investigación y construcción de la historia cercana, que se refiere al contexto en que se desenvuelven los educandos. La historia local está impregnada en el ser de las comunidades educativas, sus cambios, continuidades y discontinuidades, pero ha sido dejada en el olvido en la formación básica y media secundaria. Es menester volver a posicionar la historia local en la básica y media secundaria por las siguientes razones que concluye (Zuluaga, 2006)".

La historia local recupera la vida cotidiana como vida y, poniendo a los individuos en su realidad diacrónica activa, los presenta estableciendo relaciones con los otros individuos y va descubriendo acciones, actividades y conductas propias de las comunidades estudiadas, en ejercicio de una cotidianidad activa. Finalmente, no podemos negar que la amplitud y variedad de las formas de hacer historia local dificultan hablar de una escuela, pero si se debe reconocer que ella abre nuevos horizontes, tanto en la ampliación de escala, como en "ampliar hacia abajo la noción histórica de individuo" en una preocupación permanente por los marginados y excluidos (p.9). 
Como docentes de historia y sociales tenemos una gran responsabilidad en la construcción del ideal de nación y de identidad, y sobre todo de la formación de una identidad histórica y cultural y sentido de pertenencia en los educandos que se sientan parte de un lugar como lo dice (Miranda, 2011):

"Es significativa la importancia que tiene para el individuo reconocerse como parte de una zona determinada, de su localidad, lo que no implica perder los lazos con la nación y el mundo (todo lo contrario, los afianza), pues al identificarse más con su lugar de origen se puede apreciar mejor el lugar que se ocupa en la patria y en la humanidad. Por tanto se considera válido que: "Una fuerte y positiva identidad nacional presupone sentimientos de pertenencia, satisfacción y orgullo de esta pertenencia, compromiso y participación en las prácticas sociales y culturales propias". La identidad es un fenómeno subjetivo, que pasa por emociones y sentimientos. (p.2)"

Cada comunidad tiene dinámicas diferentes respecto a otro, y por eso es de gran relevancia en el ámbito educativo la aplicación de proyectos de aula cuyo objetivo sea el rescate de las identidades históricas y culturales de las localidades a través de una cátedra de historia local que motive al educando a indagar y aprender sobre el pasado de su barrio, municipio y su región para entender el presente que le rodea y adquirir sentido de pertenencia por el terruño sin caer en nocivos regionalismos o nacionalismos.

Enseñar ciencias sociales y específicamente historia en básica y media secundaria representa un reto para los docentes actualmente, ya que los estudiantes se mueven a un ritmo más rápido; están inmersos en la gran aldea global que ha ido homogeneizando las comunidades a través de los medios masivos de comunicación en especial las redes sociales y el internet.

En el quehacer docente y la reflexión pedagógica y social surge el interrogante ¿cómo formar identidad y sentido de pertenencia por el terruño de los educandos a través de la enseñanza de la historia local?, una de las estrategias utilizadas para esto son las microhistorias que se encuentran en el conglomerado de un barrio, y facilita acercar al educando desde su contexto próximo en iniciarlo en la investigación social.

Los jóvenes no advierten muchos hechos que suceden a su alrededor ya que consideran que son parte de su cotidianidad, en otras palabras, que 
son normales. Corresponde a los docentes, entonces, apropiarse de esos conocimientos, de esos hechos, de esas historias; a través de métodos y estrategias didácticas e investigativas y darles la importancia que se merecen al ser parte de su territorio identitarias para comprender el porqué de muchos eventos que se presentan a nivel local, regional y nacional, es decir, se busca concatenarlos en las diferentes escalas.

\section{Antecedentes de la educación en Colombia}

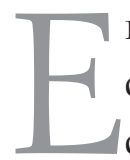

n lo relacionado con los antecedentes de la educación y la enseñanza de la historia en Colombia en el siglo XIX, en la primera mitad fue determinada por las necesidades de consolidar en los ciudadanos la idea de Estado, de nación. Para fortalecer el patriotismo por lo tanto el método Lancaster representó en ese momento la mejor alternativa económica y formativa teniendo en cuenta que el país se estaba formando y organizando después de las guerras de independencia; algunas características de este método de enseñanza las describe Sanabria, (2010)

"El currículo para las primeras letras incluía lectura, escritura y aritmética; como núcleo básico. Además de buenos modales, máximas de moral y de salud, religión, historia y geografía. la lectoescritura se aprendía a través de un ciclo de ocho clases, la aritmética por medio de un ciclo de diez clases. En este contexto, la organización por clases del Sistema Lancasteriano estaba definida, por un lado, como "un grupo de muchachos cuyo aprovechamiento esté al mismo nivel, pero sin exceder los diez por clase" y, por el otro, por la secuencia en los niveles que debía cursar cada niño para ascender en la escuela lancasteriana y en el aprendizaje de la aritmética, la lectura y la escritura. (67-68)."

En este método de enseñanza no había análisis, ni lectura crítica, ni aprendizaje significativo. Los modelos pedagógicos implantados en Colombia obedecían a las condiciones políticas y económicas del país y el sistema lancasteriano dejaba mucha libertad de creencias lo cual resquebrajó las relaciones con la Iglesia católica y para 1846 no era el adecuado. Para 1850 la enseñanza de la historia estaba regida por el aspecto social y moral, se proyectaba como un conocimiento fundamental para adquirir cultura y virtudes motivando la enseñanza de la historia patria que transmitieran el origen de la Nueva Granada.

Para el siglo XX la historia cobra un sentido monumental y se enseña la historia de los vencedores que fortalecen el sentimiento patrio, se profesionalizan 
los maestros y para 1925, Decroly es traído a Colombia con sus teorías de naturalización de la educación, que satisfaga las necesidades del niño en el ámbito personal y no colectivo, con lo que se empieza a generar un nuevo pensamiento en las formas de enseñar en la primaria; muchos eventos que suceden a partir de 1930 permiten reconstruir las disciplinas escolares, Arias, (2017), dice:

"Los años treinta marcaron una coyuntura importante en el desenvolvimiento de la historia escolar. Uno de los cambios más significativos fue la profesionalización de los maestros a través de la creación de la Facultad de Ciencias de la Educación en 1932, y su posterior transición en Escuela Normal Superior en 1936. Esta institución proporcionó la formación universitaria para los profesores de educación secundaria e inició un proceso de institucionalización de la pedagogía y de las ciencias sociales. Su trabajo fue determinante en la formación de una nueva generación de intelectuales que jalonaron el posterior desarrollo de la modernidad cultural en el país, (Pág. 7)".

Con la profesionalización de los maestros la historia y la geografía empiezan a desarrollarse como disciplinas y a establecer sus propias didácticas para la enseñanza a los niños que los aproxima a este conocimiento desde su contexto próximo siendo preparados para el trabajo y la vida ya que el modelo de Decroly buscaba en cierta manera facilitar la enseñanza y mejorar los ambientes supliendo las necesidades de los educandos. El modelo de John Dewey, realizó aportes muy interesantes como era que el discurso fuera de la mano con la práctica; esto constituye los pilares del modelo constructivista donde el alumno construye su propio conocimiento a través de las experiencias y aprende más significativamente por medio de problemas traídos de su cotidianidad para que reflexionen, analicen y busquen posibles soluciones, realizando hipótesis acerca de eso.

El papel del docente en esa perspectiva no es autoritario y es un líder intelectual; con este modelo se ven muchos cambios en la forma de enseñar que afectan notablemente la enseñanza de la historia y la geografía y poco a poco se fueron haciendo modificaciones desde el Estado para responder a las necesidades de la modernidad y la modernización en Colombia. 


\section{Las ciencias sociales en el siglo XXI}

I respecto, profesionales en la enseñanza de la historia en el país a través 1 del Ministerio de Educación Nacional, (2004) afirma:

"En efecto la enseñanza de las Ciencias Sociales no llegó a las aulas con la intención de transmitir contenidos científicos o generar aprendizajes en sentido estricto, sino de favorecer el desarrollo de una 'cultura general' y la formación de valores y una identidad nacional a través del conocimiento de los próceres, las gestas de independencia, los símbolos patrios y la descripción geográfica de los países (Pág. 11)"

A partir del 2004 los estándares y lineamientos de las ciencias sociales tienen un horizonte más claro y científico como lo expresa a continuación el Ministerio de Educación Nacional, (2004):

"Buscamos que estudiantes, maestros y maestras se acerquen al estudio de las ciencias como científicos y como investigadores, pues todo científico - grande o chico- se aproxima al conocimiento de una manera similar, partiendo de preguntas, conjeturas o hipótesis que inicialmente surgen de su curiosidad ante la observación del entorno y de su capacidad para analizar lo que observa. (Pág. 8)".

Así como lo plantean los estándares del MEN, que no solo el desarrollo del conocimiento de las disciplinas (como la historia, la geografía, la ciencia política, la economía, la psicología, la sociología, la antropología), no es lo único que pueden aprender los educandos, porque en la actualidad se reconoce que en las colectividades humanas circulan saberes culturales que son de gran baluarte por su sentido y significado que, lo producido en las academias. Se puede afirmar que el conocimiento producido en la academia son grades herramientas que pueden permitir al docente hacer un uso creativo de métodos de investigación como el método histórico, la nueva historia, la microhistoria, etc., para permitir que los estudiantes se apropien de los conceptos y puedan comprender la realidad.

Para lograr que el educando alcance lo propuesto, hay que proyectar planes de estudio o propuestas de enseñanza adaptados a las necesidades del ámbito en que está el educando, se deben replantear los contenidos desde una didáctica histórica, muy diferente a la que los docentes están adecuados lo cual confiere un nivel de dificultad al iniciar con este tipo de prácticas en cuanto al desarrollo 
cognitivo y de las competencias básicas en los estudiantes, con relación a lo anterior Prats J. , (2000) afirma:

"El estudio de la historia, en toda su complejidad, supone el uso del pensamiento abstracto formal al más alto nivel. Queda pues claro que será totalmente imposible intentar ofrecer a los alumnos de ciclos básicos $e$, incluso, medios, la selección de contenidos que pueden ser manipulados en los ciclos superiores de la enseñanza. Por lo tanto, se hará necesario una presentación de los temas de estudio en niveles adaptados a los estadios operativos del alumnado. Este trabajo constituye una de las tareas que ofrece mayores dificultades para el profesorado, dado lo complicado que resulta aislar informaciones que forman parte de un todo social dinámico. (Pág. 4)”

Los actuales estándares nos ofrecen una gran libertad en el proceso de enseñanza aprendizaje ya que la investigación científica está inmersa en cada uno de ellos, la aproximación como científico social es uno de sus grandes pilares así como las relaciones con la historia y las culturas, relaciones espaciales y ambientales, ético políticas y el desarrollo de los compromisos personales y sociales, que permiten en el proceso de conceptualización de conceptos ir descubriendo nuevos conocimientos de su entorno cercano y fomentar el desarrollo de competencias como la interpretación, la argumentación, la proposición y las competencias ciudadanas.

Desde esa perspectiva de las experiencias del maestro, la investigación y la reflexión de la práctica docente nace esta propuesta de implementación de la cátedra local doradense, en la básica y media secundaria a través de la estrategia metodológica de las historias barriales, lo que permite un acercamiento a la cotidianidad del educando al motivarlo en la reconstrucción de la historia del barrio, partiendo de enseñar al educando a preguntar y construir el conocimiento, buscando respuestas a situaciones que son de su contorno próximo como sujeto social inmerso en una comunidad, utilizando elementos de historiografía, herramientas para la obtención de fuentes primarias y análisis de fuentes primarias y secundarias que se han obtenido de los vecinos con entrevistas, videos, fotos, en fin.

Cuando proponemos la reflexión en torno a la incorporación de la perspectiva de la historia local en la enseñanza formal de la historia, estamos hablando de la posibilidad de mejorar relaciones pedagógicas dentro del aula, de una aproximación activa al proceso de enseñanza- 
aprendizaje del saber histórico, de una acción transformadora donde los alumnos puedan no solo opinar, sino también actuar sobre aquello que les interesa dentro de su institución educativa, en su municipio, en su comunidad, en su barrio, en su casa: en su vida. Esto brinda la posibilidad de que ellos se apropien de la historia, a partir de la construcción de los hechos relevantes e invisibilizados de su cotidianidad como definición de la existencia humana.

\section{Diseño, implementación y sistematización de la cátedra local doradense}

Tra propuesta de diseño, implementación y sistematización de la catedra local doradense, tiene como objetivo formar identidad histórica y cultura y sentido de pertenencia por el lugar o lugares que habitan los educandos de grado 7 de la Institución Educativa Dorada, e iniciarlos en la investigación social a través del método histórico y para esto es de gran ayuda los planteamientos de Joaquim, (2001):

"En el primer caso, no se pretende que el resultado del aprendizaje sea la elaboración de la Historia (con mayúsculas), sino adiestrar al alumno en el método histórico para que sea capaz de comprender cómo se alcanzan los conceptos y las leyes sobre el pasado. Por lo tanto, se puede aspirar a trabajar algún aspecto del aprendizaje sobre elementos sacados del entorno. Los vestigios cercanos pueden permitir ejercitarse en el dominio de la cronología, y ser útiles para elaborar aprender a formular hipótesis, para aprender a analizar alguna fuente histórica o, simplemente, para realizar tareas de clasificación. (Pág. 71)”.

En el proceso de sensibilización del estudiantado y docentes de grado 7, se utilizaron dos videos sobre la ciudad de La Dorada y diapositivas haciendo un contraste entre fotos viejas y antiguas de la localidad, y que identificaran donde estaban ubicados esos lugares, abordamos el tema de la navegación y del ferrocarril con imágenes antiguas; se pudo observar que la imagen conecta más fácilmente y genera empatía y curiosidad, pero también sorpresa al reconocer a su localidad y valorar su terruño y sentirse parte de un conglomerado social con costumbres y rasgos culturales afines y salir a flote el sentido identitario de pertenencia a su municipio

Con base en esta afirmación y desde el contexto cultural en el que se desarrolló esta propuesta, es importante aclarar que los educandos de la institución 
educativa de grado 7 y 11 , en su mayoría son jóvenes que pertenecen a una población casi que nómada, sin raíces definidas en los barrios, ya que la ciudad de La Dorada, debe su fundación a la demanda y oferta de empleos que se generaron con la navegación por el río Magdalena, al convertirse La Dorada en un puerto muy importante a comienzos del siglo XIX, llegando muchos habitantes oriundos de otros departamentos, conformándose así una cultura cosmopolita; posteriormente, la Guerra de los Mil Días afectó las dinámicas de desplazamiento y la colonización antioqueña se hizo evidente con la oferta de empleos por la construcción del tramo del ferrocarril Yeguas - La Dorada, lo que atrajo mucha población que estaba desempleada y al terminar las obras decidieron quedarse y dar vida a este municipio; cada uno de sus barrios, sus orígenes obedecen a que la población fue en aumento requiriendo la adquisición de nuevos lotes para la comunidad.

Actualmente la ciudad de La Dorada, se sostiene de una economía basada en el comercio, la ganadería en manos de unos pocos y la pesca ya en detrimento, por la contaminación del río Magdalena y a esto se le agrega la corrupción política que no permite el desarrollo en las comunidades y que los dineros sean invertidos para un desarrollo sostenible.

La falta de empleo estable, ofertas temporales por la ruta del sol, por algunos proyecto que duran por lapsos de años y que atrae población de otros lugares o hace que los que están en el municipio migren constantemente; es por esta razón que nuestra institución educativa en los últimos años se ha visto afectada por la falta de estudiantes debido a la condición de la población flotante y también porque La Dorada se ha ido extendiendo al norte y la institución queda ubicada en el sur del municipio.

Para concluir con la descripción del contexto del educando, se puede declarar que la ciudad de La Dorada, ha estado enmarcada en una colonización y poblamiento cosmopolita debido a sus condiciones geográficas, lo que ha dificultado a través de los años establecer una cultura y una identidad propia, pero ante la iniciativa de unos pocos y algunas autoridades y frente a las exigencias económicas del mundo globalizado ha sido necesaria la construcción de esta identidad con símbolos propios del paisaje natural y todo lo que esto conlleva para que desde las aulas se aporte a la diferenciación de un grupo cultural para definir su identidad dentro de la nación colombiana. 
De esta manera investigar desde lo local significa como lo plantean los actuales lineamientos curriculares para el área de Ciencias Sociales, recuperar la finalidad de la educación y de las ciencias sociales: "comprender el mundo, vivirlo y transformarlo", actividades que promueven la formación de ciudadanos con capacidad de optar, de asumir, a la manera como lo plantea Estanislao Zuleta, la angustia de pensar por sí mismos. Esto nos guía a rescatar la idea del maestro como puente unificador entre lo que piensa y siente el estudiante y la realidad como debe ser abordada desde lo académico por el mismo.

En este proceso de sensibilización el sentimiento que se esperaba despertar fue la curiosidad y sobre este último se enfatizó para incentivarlos a ser investigadores sociales y que se formaran por grupos según el barrio que habitan, surgieron seis grupos para iniciar a ser instruidos en el método histórico y manejo de fuentes.

Teniendo en cuenta lo anterior, en la enseñanza de la historia local es importante que el educando se sienta como un investigador y se despierte en él el deseo de aprender y resolver preguntas, dando relevancia el hecho de que los alumnos logren una postura crítica, conocer y comprender los métodos a partir de los cuales se construye el conocimiento histórico. Prats J. ( 2011) señala:

"La historia es una disciplina que sin análisis crítico no existiría. Por lo tanto, enseñar y aprender historia es estimular el pensamiento; también en este punto sucede que, cuando los docentes renuncian a enseñar el análisis crítico de las fuentes, en realidad no enseñan historia sino una narración mítica y frecuentemente adulterada del pasado. Por lo tanto, éstas son las dos principales funciones que ha de tener la historia en la formación de la etapa adolescente. El desarrollo del pensamiento crítico en Historia puede y debe hacerse a partir de técnicas elementales de crítica de textos; en estos casos los análisis consisten en plantear cuestiones tales como: ¿quién lo escribió? ¿para qué y para quiénes lo escribió? ¿cuándo y dónde se escribió? ¿en qué bando, facción o ideología se hallaban el autor o autores del texto? Todos estos interrogantes, que constituyen la base del análisis crítico de textos, deberían necesariamente formar parte del método que la escuela enseñe. (Pág. 44)".

Enseñar historia utilizando el método histórico motivó notablemente a los educandos, aunque al iniciar hay múltiples expectativas, siempre hay sorpresas 
en el quehacer docente del proceso de enseñanza-aprendizaje, aprendiendo del error, del fracaso, del intento, pero que en últimas se convierte en un banco de experiencias que ayudan a edificar y mejorar este proceso desde la reflexión pedagógica al utilizar un modelo educativo o combinar algunos.

Cada secuencia didáctica se fue diseñando según las posibilidades que el medio próximo brindaba a los educandos y al docente y como iba asimilando la utilización de los instrumentos para la recolección de la información sobre su barrio; la dificultad con la que nos encontramos fue con las acciones comunales de los barrios, que en algunos han sido cerradas y no hay documentos sobre la fundación del barrio, o acontecimientos importantes, en cuanto a las fuentes iconográficas las fotos de los barrios no fue posible encontrar, pero si pudimos usar las fuentes orales de personas que han vivido más de 50 o 60 años en el barrio y con ayuda de ellos se realizó prácticas de redacción de la historia del barrio. Con respecto a lo anterior Pages, (1994) dice:

"El profesorado ha de procurar facilitar contenidos para que los estudiantes puedan evaluar las evidencias de los hechos, detectar inconsistencias y contradicciones en las interpretaciones, diferenciar y evaluar las informaciones sobre los hechos de las opiniones, sacar conclusiones, construir y validar hipótesis, formular preguntas, realizar deducciones, identificar supuestos subyacentes y emitir sus propias opiniones con conocimiento de causa. Se requiere predisponer al alumnado para que quiera pensar e intervenir en la construcción de su futuro personal y social. (p.7)."

En este proyecto de aula de implementación de la cátedra local doradense, las secuencias y guías didácticas han sido diseñadas según la evolución de los temas y las actividades de los grupos y para motivarlos en la investigación social.

Cada secuencia didáctica se encuentra publicada en el blog de ciencias sociales de cátedra local y pueden ser descargadas, cada una de ellas aborda siete aspectos tales como los datos generales, objetivos, competencias y estándares del MEN, metodología, recursos, evaluación, instrumentos de evaluación y bibliografía.

La primera experiencia en el trabajo de campo, no arrojó los productos esperados en cuanto a las fuentes consultadas en todos los barrios, pero en 
algunos los estudiantes pudieron realizar las entrevistas a personajes del barrio o juntas de acción comunal, pero la aplicación del método histórico y la comprensión del mismo fue muy prolífera en el aspecto cognitivo, ya que al utilizar el método para dar respuesta a un interrogante de su entorno próximo este tipo de aprendizaje se torna significativo, porque no solo lo lee, escucha la explicación sino que lo utiliza para entender la realidad que le rodea.

Se construyeron líneas del tiempo con ayuda del análisis cronológico de las tres monografías que han sido escritas de La Dorada, partiendo desde el descubrimiento de América, conquista, colonia para que el educando se ubique en el tiempo histórico y cronológico de los acontecimientos que afectaron el devenir de La Dorada.

El diseño e implementación y sistematización de cátedra local doradense en los estudiantes de 7 de básica secundaria y media vocacional, se ha fortalecido con el análisis de las diversas monografías que hay en La Dorada, algunas crónicas de Fray Pedro Aguado con respecto a los indígenas pentágonos, lecturas de noticias de los periódicos El Tiempo y El Espectador cuando el auge del narcotráfico y el paramilitarismo que tanto afectó a la localidad. Cada monografía nos aporta fuentes primarias y secundarias que son herramientas para la interpretación de textos y comprensión de contextos de diferentes épocas por las que atravesó La Dorada, hasta la actualidad y que los estudiantes no conocían, ya que no han sido utilizadas como medio de consulta.

Las secuencias didácticas planeadas para convertir al educando en un científico social de su cotidianidad, van de lo particular a los general, buscan provocar en el educando interés por conocer más de su entorno, de la comunidad que lo rodea, al visitar el barrio, investigar la historia con los vecinos, obtener fotos si las hay del barrio antes para hacer comparaciones con la imagen urbana actual, hacer entrevistas relacionadas con las juntas de acción comunal y hechos sucedidos en el país, región y municipio que hayan afectado a la comunidad, su importancia, su evolución, su legado y su constitución actual.

La transversalización del proyecto la aplicamos en áreas como artísticas y ética y valores, enfatizando en el rescate de la idéntica histórica y cultural para formar sentido de pertenencia, a través de una muestra de pintura y dibujo de sitios emblemáticos de la ciudad de La Dorada, realizados por los estudiantes y algunos padres de familia, la realización de un mural en la entrada del colegio 
para la promoción de la cátedra local doradense, integrando el currículo con ética en el rescate de los valores como son el sentido de pertenencia, identidad cultural y trabajo en equipos colaborativos.

Esta experiencia de aula permite un ensanchamiento de la práctica docente, para darle más rigor académico en cuanto a la importancia que tiene la investigación en el aula y fuera de ello y como incentivar a los chicos y chicas a la búsqueda del conocimiento inmersa en la cotidianidad

No ha sido fácil la construcción de los contenidos según la necesidad del educando y del contexto, porque para ello es necesario recurrir a fuentes secundarias y primarias que ayuden a estructurar una secuencia didáctica que permita desaprender para volver a aprender como docente en las dinámicas pedagógicas, constituyendo un reto total volver a programar la forma de enseñar ciencias sociales después de la cualificación lograda en la maestría.

Terminada la implementación en el aula quedan seis secuencias didácticas de cátedra local doradense para grado séptimo que son abordadas desde el barrio, el método histórico, reconocimiento de fuentes primarias y secundarias, clasificación y utilización de las mismas, líneas de tiempo, adquisición de conocimientos de identidad histórica y cultural del municipio, análisis de problemáticas sociales evidenciadas por los educandos.

El producto final, el proceso de sistematización y análisis de la experiencia la cual considero muy enriquecedora en cuanto a una nueva manera de enseñar historia y acercar lo que se aprende en la Universidad a los estudiantes de básica secundaria. Es un reto que vale la pena tomar ya que como maestros frecuentemente nos quedamos en un lugar de confort intelectual y no avanzamos, lo cual no permite también que nuestras estrategias didácticas tengan una mejor perspectiva para convertir las ciencias sociales en un aprendizaje significativo para los educandos, pero a través de esa práctica hay un crecimiento intelectual, pedagógico y personal con una nueva visión para enseñar ciencias sociales y con herramientas de más rigor académico como son la investigación social aplicando el método histórico en el aula y fuera de ella.

Este proyecto de aula o experiencia de investigación pedagógica deja sistematizado un blog de acceso libre donde están publicadas las secuencias didácticas, recursos utilizados y productos realizados por los estudiantes, las 
evidencias de las entrevistas, audios y trabajos artísticos desarrollados por los estudiantes y todo esto se expuso en un evento de difusión para docentes, autoridades de la localidad y estudiantes.

\section{Conclusiones}

n el campo disciplinar de la enseñanza de la historia creo que este $\checkmark$ tipo de experiencias son un reto que debemos afrontar para lograr $\_$interesar a los educandos en las ciencias sociales y en el conocimiento y construcción de la historia a través del método histórico, donde el educando aprenda haciendo.

La historia local como una estrategia didáctica para introducir al estudiante en la investigación histórica abre un sinfín de posibilidades de acortamiento de distancias entre lo enseñado en la academia y lo enseñado en la escuela, para que el educando comprenda la historia y en particular la de su contexto. Por ello, es prioritaria una visión que le ofrezca al alumno conocer los elementos y los métodos de hacer historia, esto con el fin de generar educandos con un pensamiento crítico y creativo y a su vez formar sentido de pertenencia e identidad por el lugar donde vive.

La enseñanza de las ciencias sociales debe trazar un puente entre el educando y su cotidianidad, donde adquiera importancia un área o asignatura que ha sido vista durante muchos años como un cúmulo de datos sin importancia, sin relación, porque cuando se enseña ciencias sociales desde un proyecto de aula que involucra los intereses del educando para llevarlo a la reflexión, al pensamiento crítico, surgen interrogantes por lo que pasa a su alrededor e ir en búsqueda de un conocimiento que le explique las causas del presente, de su contorno próximo y adquiera destrezas como científico social que interpreta el antes y el después, en esta deconstrucción y construcción del conocimiento.

Enseñar historia local, desde el barrio, con las herramientas que nos ofrece la historiografía y la caja de herramienta de los historiadores de oficio, es como si después de un gran nubarrón de enseñanza transmisionista y de memorización se desplegara un arcoíris de unidad entre la academia y la práctica. Uno que permita ver que no está lejos llevar a las aulas el espíritu de la investigación social desde la búsqueda, la formulación de preguntas, el ensayo y el error, para sacar conjeturas ejercitando intelectualmente la mente del educando, pero inicialmente la de nosotros como docentes, facilitadores del proceso de enseñanza-aprendizaje, que debemos aprender a enseñar desde 
la pregunta que no salga de nosotros sino del educando, para que las ciencias sociales sean significativas para su vida, para la construcción de conocimientos útiles de ser usados en sus procesos de aprendizaje para la vida.

La tarea del maestro es ser un facilitador de procesos que transforme la dinámica de enseñar historia, por ayudar a construir historia, proyectos que impliquen utilizar otras áreas del conocimiento y que activen el espíritu del investigador social en búsqueda de respuestas a los interrogantes que se plantea y también explorar soluciones a diversas situaciones que en el proceso surgen estimulando el desarrollo cognitivo del educando.

Este proyecto de aula, al ser aplicado por primera vez en la institución, con los educandos del grado 7 representa una puesta en escena de un guión experimental, donde se pudo observar en las diferentes clases y salidas de campo como este conocimiento era nuevo para ellos, ya que no se ha enseñado ciencias sociales con énfasis en la investigación. En lo cognitivo es un comienzo muy bueno en la investigación social, ya que se toma como laboratorio el terruño del educando, se valoran los testimonios de los habitantes del barrio, sus experiencias, formando en los jóvenes involucrados competencias ciudadanas y además un valor agregado de respeto y honra a los mayores que tienen mucho por contar.

El tiempo histórico en el que estamos demanda de los docentes de ciencias sociales cualificación en el aspecto histórico y en los métodos propios de la investigación social como pilar de nuestras vidas, asumiendo desafíos en el campo educativo, ya que las sociedades están en constante cambio. Es por eso que nuestro quehacer docente va más allá de transmitir cierto tipo de conocimientos, y debe estar encaminado a motivar a los estudiantes a ser científicos sociales y encontrarle significado y utilidad a las ciencias sociales en aras de contribuir a la construcción -y reconstrucción- del tejido social de su comunidad.

Estamos convencidas de que la utilidad de la enseñanza de la historia local para la formación de las identidades culturales e históricas radica en comprender que la historia local está en construcción y en algunos casos invisibilizada, y que tenemos un gran cúmulo de talentos en las aulas esperando a ser seducidos por una buena propuesta didáctica que parta desde su cotidianidad, y siembre la semilla del saber sabio de la investigación social y el oficio del historiador y los saque del confort de "espectador" al de "protagonista" de su devenir y 
constructor de su historia, y es aquí donde la transposición didáctica se hace efectiva y el aprendizaje es significativo.

¡Hay tanto por descubrir en el entorno del educando! Ese es el laboratorio ideal para construir un pensamiento crítico e histórico, y desarrollar habilidades y destrezas conceptuales, comunicativas y ciudadanas, al formar en el estudiante la empatía por el otro, mejorando también las relaciones interpersonales en todos los aspectos, al valorar la importancia de los abuelos y la memoria colectiva para mostrar una historia nueva que no se ha escrito en ninguna monografía de las que existe en La Dorada.

Los jóvenes desconocen tanto su pasado lejano como el reciente, aunque viven en un mundo globalizado, inmersos en el uso de las tecnologías de la información y las comunicaciones, que a pesar de acercarlos a la información, a lugares desconocidos y distantes, al conocimiento de sus culturas ancestrales, poco o nada se han aprovechado para reconstruir y dar a conocer esa historia que no se ha contado, la historia de los personajes de la vida cotidiana del barrio, las instituciones educativas donde pasan la mayor parte de su tiempo, la ciudad, la región.

Debido a esto, es fundamental que desde la escuela los docentes implementemos el uso adecuado de esas TIC, sacándoles el mayor provecho posible. Y esa es una labor que nos compete, más que a nadie, a nosotros los docentes de ciencias sociales o de historia, para recuperar esa historia desde abajo e invisible, haciéndola visible y dándole el valor que merece en nuestra sociedad. Sociedad que ha pasado por múltiples procesos generadores de violencia, que han afectado de una u otra manera a todo el pueblo colombiano.

La implementación de la cátedra local solo es el inicio de una transformación en la enseñanza de las ciencias sociales y de la historia en la Institución Educativa Dorada. Es un proyecto en construcción que requiere pasión, conocimiento y vocación docente para lograr un impacto a mediano y largo plazo en el municipio.

Aprender a hacer la transposición didáctica como lo propone Chevallard, representó un reto para nosotras como docentes licenciadas en Ciencias Sociales en el ámbito didáctico ya que el conocimiento adquirido en la maestría de historia implicaba un nivel de profundidad que no podíamos así no más, compartirlo con nuestros estudiantes; adaptar este conocimiento del oficio 
del historiador y las diversas técnicas y conectarlas coherentemente con los estándares del Ministerio de educación para grado 7 y 11 y guiarlos a la construcción de la realidad social e histórica del municipio en las mentes de nuestros educandos, requirió hacer una instrumentalización rigurosa pero flexible de algunas estrategias metodológicas de enseñanza que nos permitieran la transformación de esos conocimientos para que los educandos aprehendieran y se hiciera una transferencia del saber, cuando nosotras mismas no teníamos experiencias utilizando el método histórico ni teníamos un conocimiento muy profundo del oficio del historiador.

En el proceso de transposición didáctica es fascinante observar la conversión de los conocimientos adquiridos por los estudiantes en un aprendizaje significativo para ellos, lo cual les permite pasar de ser agentes pasivos a ser actores comprometidos, críticos y propositivos en el proceso de aprendizaje. Además, al apropiarse de otros escenarios de enseñanza-aprendizaje, se motiva a los educandos a hacer cosas novedosas a partir de sus intereses, lo cual es muy prolífico, aunque se torna dispendioso romper los paradigmas y esquemas de pensamiento y conducta transmisionistas, las cuales son perjudiciales en un proceso de enseñanza-aprendizaje que pretenda contribuir a la formación de sujetos críticos con pensamiento histórico.

Al observar estos procesos, como docentes, sentimos una enorme satisfacción, ya que las ciencias sociales escolares adquieren mayor utilidad para nuestra comunidad. No en vano, el currículo se volvió interesante para ellos, ya que estudiar e investigar sobre el pasado de su contexto próximo le ayuda a formar un pensamiento histórico y social, y sienta las bases para la formación de identidad cultural y sentido de pertenencia hacia su terruño, conceptualizando nuevos saberes, conocimientos y técnicas de investigación social útiles para nuestra sociedad.

Uno de los logros alcanzados es la implementación de la cátedra local en el plan de estudios del área de Ciencias Sociales, para posteriormente ser incluida en el Proyecto Educativo Institucional, ya que empezamos con la historia del municipio y es mucho lo que hay por tratar en historia local, como la reconstrucción de la historia de nuestra Institución Educativa, que está a las puertas de cumplir 70 años de funcionamiento. Esta propuesta es un abrebocas de posibilidades didácticas teniendo en cuenta el entorno del estudiante y para dar un paso más adelante, hacia poder involucrar un poco más a toda la comunidad educativa que en su mayoría docentes, estudiantes 
y padres de familia, fueron sensibilizados ante la historia que nos rodea, que está invisibilizada, pero de la cual hacemos parte.

\section{REFERENCIAS BIBLIOGRÁFICAS}

ARIAS, O. (2017). Continuidades y discontinuidades de la historia escolar en Colombia. Pedagogia y saberes No. 42,7 .

JOAQUIM, P. (2001). Enseñar historia: Notas para una didactica renovadora. on-line: histodidactica.

MINISTERIO DE EDUCACIÓN NACIONAL. (2004). http://www.mineducacion.gov.co. Obtenido de http://www.mineducacion.gov.co: http://www.mineducacion.gov.co/1621/articles-116042_ archivo_pdf3.pdf

MIRANDA, I. M. (2011). Preservar la identidad cultural una necesidad en la actualidad. Arte y Sociedad, Revista de Investigación, 2.

PAGES, J. (1994). La didáctica de las ciencias sociales, el currículum de historia y la formación del profesorado. Teoria y práctica de la educacion, 7.

PRATS, J. (. (2011). Enseñanza y aprendizaje de la historia en la educación básica. México: Universidad Pedagogica Nacional.

PRATS, J. (2000). Dificultades para la enseñanza de la historia en la educacion secundaria. Teoria y didáctica de las ciencias sociales , 4 .

SANABRIA, M. F. (2010). Enseñando mutuamente: Una aproximación al metodo lancasteriano y su apropiaciòn en Colombia. Rhec. Vol 13, 67-68.

SÁNCHEZ, P. R. (2014). Enseñar a investigar. México: Universidad Nacional Autónoma de México.

ZULUAGA, U. F. (2006). Unas gotas; reflexiones sobre la historia local. Colciencias , 9. 